\title{
Role of reactive power (STATCOM) in the planning of distribution network with higher EV charging level
}

\author{
Arsalan Hussain Zaidi \\ Technological University Dublin, arsalanhussain.zaidi@tudublin.ie \\ Keith Sunderland \\ Technological University Dublin, keith.sunderland@tudublin.ie \\ Michael Conlon \\ Technological University Dublin, michael.conlon@tudublin.ie
}

Follow this and additional works at: https://arrow.tudublin.ie/engscheleart2

Part of the Electrical and Computer Engineering Commons

\section{Recommended Citation}

Zaidi, A.H., Sunderland, K. and Conlon, M. (2019), Role of reactive power (STATCOM) in the planning of distribution network with higher EV charging level. IET Gener. Transm. Distrib., 13: 951-959. DOI: 10.1049/ iet-gtd.2018.6046

This Article is brought to you for free and open access by the School of Electrical and Electronic Engineering at ARROW@TU Dublin. It has been accepted for inclusion in Articles by an authorized administrator of ARROW@TU Dublin. For more information, please contact arrow.admin@tudublin.ie, aisling.coyne@tudublin.ie, gerard.connolly@tudublin.ie.

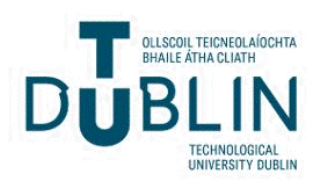




\title{
Role of reactive power (STATCOM) in the planning of distribution network with higher EV charging level
}

ISSN 1751-8687

Received on 2nd February 2018

Revised 27th August 2018

Accepted on 15th November 2018

E-First on 7th March 2019

doi: 10.1049/iet-gtd.2018.6046

www.ietdl.org

\author{
Arsalan Hussain Zaidi ${ }^{凶}$, Keith Sunderland ${ }^{1}$, Michael Conlon ${ }^{1}$ \\ ${ }^{1}$ School of Electrical and Electronics Engineering, Dublin Institute of Technology (DIT), St. Kevin Street, Dublin 8, Ireland \\ 凶E-mail: arsalan.zaidi@mydit.ie
}

\begin{abstract}
In recent years, new trends in electrification of the transport sector have been a major concern for distribution grid operators. New types of flexible, uncontrollable loads, such as EV, influence the reliability of distribution networks. This work is related to the distribution system planning framework, with a particular focus on uncoordinated flexible EV loads. The main focus is the enhancement of the hosting capacity of EVs on distribution networks, while maintaining power quality (especially voltage magnitude and voltage unbalance), which is ultimately a pre-requisite for increasing prosumer engagement. Several EV charging scenarios, in the context of UK/Irish distribution networks with increased penetration of EV prosumers are considered. The results show that reactive power compensation through STATCOM, in the context of EV integration, can provide continuous voltage support and thereby facilitate $90 \%$ penetration of network customer EV connections at a normal EV charging rate (3.68 $\mathrm{kW}$ ). If fast charging (up to $11 \mathrm{~kW}$ ) is employed, $<30 \%$ of network EV customers can be accommodated due to bottlenecks presented by the substation transformer loading.
\end{abstract}

\section{Introduction}

Electric vehicles (EVs) are considered as a potentially effective technological response to address road transport emission targets. Many cities in tackling air pollution are considering policies to actively increase the number of EVs on their roads and ban diesel cars altogether by 2025 [1]. Examples include Paris, Mexico City, and Athens. Electric transportation including Electric Buses (EBs) and EVs is one of the important measures for greenhouse gas reduction. Governments are proposing many subsidy measures to enhance people's willingness to use EBs and purchase EVs. A 'Zero Emission Urban Bus System project' reveals data from 19 public transport operators, covering 25 European cities, were published as part of the Electrical Bus (e-bus) strategy for 2020 [2]. More than 2500 EBs are currently operating in these cities, representing $6 \%$ of the total fleet of 40,000 . However, the potential for electrical transport to reduce greenhouse gas emissions depends on the nature of electricity generation used to charge electrical transport batteries. Although for the sake of simplicity, EVs are considered in this work, integration of EBs in distribution network is also likely to be increased in the near future. Energy demand is increasing, particularly in urban areas. So along with the potential for the mass penetration of new technologies such as electrical transportation and micro-generation [3], the power quality associated with distribution networks is likely to be affected. However, the smart control of distribution generation, demand response services, and electric transportation is also essential. Promoting EV use in urban environments has practical implications around electric-grid capacity for mass EV charging, as the increased capacity required by increased uptake of EV's will require significant infrastructure investment to upgrade the existing grid supply. In the last two decades, a significant amount of research has been carried out to analyse the impact of charging and discharging of EVs on power systems [4]. Currently, research is more focused on either steady-state or time-domain simulations to study different EV charging scenarios and impacts on the distribution network. However, the single snap shot over a limited or short time period is highly unlikely to adequately present the load flow problem.

Distribution networks are designed based on a 'fit-to-forget' approach [5] without considering uncertainties in a deterministic way. This approach will not work with increasing penetrations of low carbon technologies (LCTs). A centralised, fast responding and controlling device is consequentially required to mitigate powerquality issues. Voltage problems can be solved by reinforcing the distribution network, although upgrading existing network infrastructure requires a significant amount of investment. Another prospective solution is installation of on-load tap chargers (OLTC), although in Irish/UK distribution networks, OLTC's are not commonly used. OLTC are only able to mitigate the voltage problem, so voltage unbalance, exacerbated by single-phase distributed load/generation connections, remains an issue. In [6], decoupled OLTC control is proposed to increase hosting capacity of PV from 20 to $70 \%$. The results are promising but voltage unbalance factor remains between 2 and $3.5 \%$, which is a relatively high value. OLTC control is not able to reduce voltage unbalance, which is ultimately pre-requisite to increase LCT (solar, wind, and EV) penetration/hosting capacity in the distribution network. Another prospective solution is PV inverter dispatch of reactive power. In [7], reactive power support is proposed based on inverter ratings. Although only limited reactive power support is possible due to the power rating of the inverters, additional power losses can limit the effect on voltage profile. In [8], a hybrid voltage scheme based on real and reactive power management, embedded with centralised OLTC is discussed. The results are quite promising but the effects of reactive power is limited and not all distributionlevel transformers are equipped with OLTC functionalities.

In the LV network analysis considered in [9], stochastic analysis is carried out using Monte-Carlo simulation (MCS) based on PV penetration at different locations in the network. Dynamic modelling of custom power devices such as distribution static compensator (D-STATCOM) is presented. D-STATCOM is successful in reducing the voltage unbalance, although the study focuses primarily on limiting the voltage unbalance factor and optimal placement of the D-STATCOM. In [10], a comprehensive study examines two different custom power devices, namely DSTATCOM and dynamic voltage restorers (DVR). Stochastic analysis is presented in [11] based on MCS to investigate uncertainties of load, PV rating, and location. It is noted that 20,000 random samples are taken (to avoid pre mature convergence) with 10-min resolution input data. Stochastic analysis results, based on MCS, are highly dependent of the quality/ accuracy of input data/parameters. It is noted in the literature that 5-min resolution input data are preferred in performing 


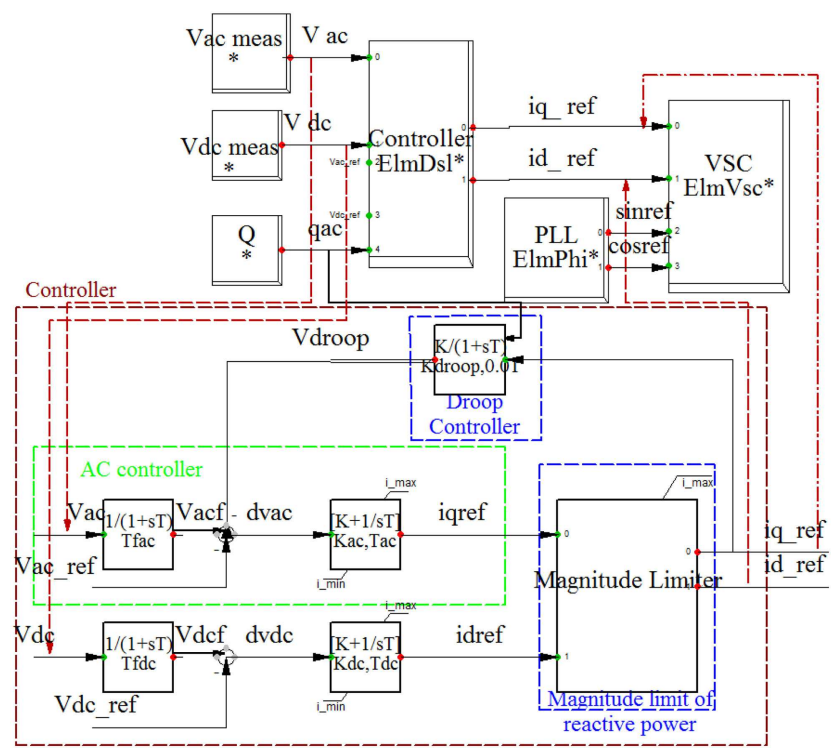

Fig. 1 Implemented frame of D-STATCOM controller

probabilistic analysis using MCS. Different random sample sizes of 100 and 1000 are considered in simulation and results are compared. Mismatch between the two sets of results cases was nominal [12]. It is noted that high-resolution data require less input random sampling to acquire accuracy while reducing computation burden at the same time. Hence, high-resolution data are employed in this work. In order to overcome the uncertainties regarding EV load, detailed understanding of consumer behaviour is necessary. To replicate the realistic charging pattern, consumer driving behaviour needs to be considered.

This paper discusses the role of reactive power in EV charging and battery sizes variation scenarios. The uncertainties associated with battery state of charge (BSOC) are accommodated through statistical PDF application. The stochastic profile of EV loads are considered based on random placement of EV load in the network.

The emphasis remains on the dynamic modelling of individual EV loads at each location based on battery size and state of charge. Distribution System Operators (DSOs) commonly use After Diversity Maximum Demand (ADMD) values to design networks. The battery charging/discharging profiles are considered based on a rectangular distribution [13] like once battery is connected to the LV network, it will remain connected until it is completely charged. Charging rates of 3.68 and $11 \mathrm{~kW}$ (single phase) are considered. A Grid to Vehicle $(\mathrm{G} 2 \mathrm{~V})$ operating mode based on uncontrolled charging, with $90 \% \mathrm{EV}$ penetration at an instance, is considered, in order to define the optimal size of the STATCOM to maintain voltage levels.

A representative Irish (urban) distribution network is modelled to include high-resolution time variant EV loads. It is assumed that EVs are removed from the consumer-grid connection between 9:00 am to 5:00 pm during office hours. If for the remaining time $(16 \mathrm{~h})$ they are connected to the grid (charging), even with a particular driving/travelling distance/period, there will be (in the context of a charging battery) inevitable fluctuations as a consequence of EV. Travelling requirements of passenger cars are considered in order to design more realistic EV battery load profiles. In general slow charging $(3.68 \mathrm{~kW})$ can take $\sim 8 \mathrm{~h}$ to fully replenish an EV battery from a discharged state. Fast charging $(7-22 \mathrm{~kW})$ will take around 3 to $4 \mathrm{~h}$ to fully replenish an EV battery from zero charge [14]. A normal battery size is considered to be $20 \mathrm{kWh}$, but recent advancement in EV battery capacity suggests a $40 \mathrm{kWh}$ battery is available on the market and e-Bus battery capacities are in the order of $200-300 \mathrm{kWh}$ [11]. It is not practically possible for frequent EV users to connect $40 \mathrm{kWh}$ battery for $10-12 \mathrm{~h}$ with a $3.68 \mathrm{~kW}$ single-phase charger [15]. In the UK/Irish context, the DSO needs to consider a higher EV charging rate, and an accompanying increased facility, to accommodate the new trends in the electrification of the transport sector. In Ireland, households are connected via a single-phase supply. The work presented here is based on the impact of higher EV charging rate on single-phase connected distribution network and STATCOM ability to mitigate the voltage magnitude and voltage unbalance issue. STATCOM is very versatile device and available in the market with a range of power rating but the distribution-level (D-STATCOM) power rating was selected for this work.

\section{Method}

\subsection{STATCOM}

2.1.1 Power flow analysis: STATCOM implemented in distribution networks are known as 'D-STATCOM'. D-STATCOM has the advantage that they can inject almost sinusoidal three-phase balanced current. D-STATCOMs are characterised as reactive output power (capacitive or inductive) only compensators. In this regard, the compensator uses reactive power to control the voltage at given terminals and to maintain desired power flow under disturbances. The control requirement of the compensator depends on power flow variation and associated requirements to stabilise the power system. The basic compensation needs to fulfil one of two main categories: direct voltage support (to maintain voltage in case of disturbances) and transient and dynamic-stability improvements. The D-STATCOM, in this regard, is essentially designed as a static generator to facilitate direct voltage support [16]. The D-STATCOM model is designed as a current source to produce reactive power. The concept of reactive power generation is similar to synchronous generation, where reactive power output is changed by excitation control. The equivalent circuit model is taken from [17]. The control signals are identified as id ref $(d$-axis reference current in p.u) and $i q_{-} r e f(q$-axis reference current in p.u). Fig. 1 illustrates the design concept of D-STATCOM and is explained below [18] based on power flow relationship.

$$
\begin{aligned}
i_{1}= & \left(i d \_r e f \times \cos u-i q \_r e f \times \sin u\right) \\
& +j\left(i d \_r e f \times \sin u+i q \_r e f \times \cos u\right) \\
\cos u= & u_{r} / u, \quad \sin u=u_{i} / u
\end{aligned}
$$

where $u_{1}=(u \cdot(\cos u+j \sin u)=u r+j \cdot u i)$ is the complex voltage at the controlled bus, $i_{1}$ is the complex current that the D-STATCOM injects/absorbs into/from the network, $u_{r}$ is the real component of bus voltage, $u_{i}$ is the imaginary component of bus voltage, $i_{r}$ is the real component of current and $i_{i}$ is the imaginary part of current.

$u=$ positive sequence voltage in $\mathrm{p} . \mathrm{u}$

$i_{1}=$ current in p.u.

$$
\begin{aligned}
& i_{1}=\left(i d \_r e f \times \frac{u_{r}}{u}-i q \_r e f \times \frac{u_{i}}{u}\right)+j \\
& \left(i d \_r e f \times \frac{u_{i}}{u}+i q \_r e f \times \frac{u_{r}}{u}\right)
\end{aligned}
$$

The static generator is controlled in current-oriented coordinates ( $d q$ rotating reference frame), whereas the control inputs to the static generator are in a stationary reference frame. Hence, the controlled inputs of the static generator are transformed from stationary ( $\alpha \beta$ frame) to a rotating reference frame ( $d q$ frame) through the Park transformation. Based on the D-STATCOM bus connection, it is possible to calculate the apparent power.

$$
\begin{gathered}
S=U \times I^{*}=\left(u_{r}+j \times u_{i}\right) \times\left(i_{r}-j \times i_{i}\right)=P+j Q \\
P=u_{r} \times i_{r}+u_{i} \times i_{i}
\end{gathered}
$$

As the active power flow from the STATCOM is zero, $P=0$, so (3) becomes

$$
\begin{gathered}
Q=u_{i} \times i_{r}-u_{r} \times i_{i} \\
i_{i}=-\frac{u_{r} \times i_{r}}{u}
\end{gathered}
$$


If the D-STATCOM injects controllable reactive current into the system, the current magnitude can be represented as a shunt reactive current source $\left(i_{S H}=i_{1}\right)$. The reactive power exchange of the D-STATCOM with the AC system is controlled by regulating the output voltage amplitude of the voltage source converter (VSC)

$$
\begin{gathered}
i_{\mathrm{SH}}^{2}=i_{r}^{2}+i_{i}^{2}=i_{r}^{2}+\left(-\frac{u_{r} \times i_{r}}{u}\right)^{2} \\
i_{\mathrm{SH}}=\frac{u \times i_{r}}{u_{i}}
\end{gathered}
$$

Now, $i_{r}$ and $i_{i}$ can be determined with respect to $i_{S H}$, from this result, it is possible to relate the static generator to the DSTATCOM controller. It shows a direct relationship between quadrature current (id_ref, iq_ref) with respect to D-STATCOM current.

$$
\begin{gathered}
i q_{-} r e f=-i_{\mathrm{SH}} \\
i d \_r e f=0
\end{gathered}
$$

The reactive shunt currents that can be injected by the DSTATCOM are based on voltage droop characteristics (Vdroop as shown in the red box provided in Fig. 1). The slope of the droop characteristics determines the voltage regulation requirement of the system. A droop controller requires a reactive power reference value from the network. The reactive power input value is taken from the ' $Q$ ' block and sent to the controller $q a c$ signal directly into the droop controller block. D-STATCOM can be operated over a complete range even at very low change voltage level in the system (typically 0.2 p.u). Thus, the D-STATCOM is capable of maintaining the $\mathrm{AC}$ system voltage and reactive power generation independently to support voltage under abrupt system disturbances which is outside the operation range of the compensator,

2.1.2 Dynamic model: D-STATCOM as a dynamic model is based on the Milano method [19]. For brevity, the only equations used are presented in (11)-(16). A detailed and simplified modelling of D-STATCOM is comprehensively discussed in [19]. The detailed model of D-STATCOM mainly consists of three parts: the DC network, the voltage source converter, and the associated controllers.

2.1.3 DC network: The DC-side consists of a RC network connected in parallel to the DC node. $I_{d c}$ and $V_{c}$ are DC capacitor current and voltage, respectively. $R$ is the resistance and $C$ is the capacitor, $v_{d c}$ is the DC terminal voltage [19]. The differential equations are:

$$
\begin{gathered}
\dot{v}_{c}=\frac{-\left(i_{\mathrm{dc}}+v_{c}\right) / R}{C} \\
0=v_{c}-v_{\mathrm{dc}}
\end{gathered}
$$

2.1.4 VSC model: Due to the fast response of the power electronic switches and of the capacitor, in most transient stability applications, the VSC can be modelled by considering only the power balance and simplified control equations. The simplified control equations do not explicitly include the firing angle and the modulating amplitude but only consider input and output variables [20]. $p_{\text {ac }}$ and $q_{\text {ac }}$ are active and reactive powers. Hence, to regulate the active and reactive powers on the $\mathrm{AC}$ side, the control differential equations can be written as:

$$
\begin{aligned}
& \dot{p}_{\mathrm{ac}}=\frac{\left(P_{\mathrm{ref}}-p_{\mathrm{ac}}\right)}{T_{p}} \\
& \dot{q}_{\mathrm{ac}}=\frac{\left(q_{\mathrm{ref}}-q_{\mathrm{ac}}\right)}{T_{q}}
\end{aligned}
$$

2.1.5 Controller: In order to maintain consistency and provide a better understanding of the STATCOM in Fig. 1, controller equations are presented in ' $\boldsymbol{s}$ ' domain. The dynamic control equation of $\mathrm{DC}$ and $\mathrm{AC}$ voltages are

$$
\begin{gathered}
i d \_r e f=\left(V_{\mathrm{dc}}\left(\frac{1}{1+s T_{\mathrm{fdc}}}\right)-V_{d c_{-r e f}}\right)\left(\frac{k_{\mathrm{dc}}+1}{s T_{\mathrm{dc}}}\right) \\
i q_{-r e f}=\left(V_{\mathrm{ac}}\left(\frac{1}{1+s T_{\mathrm{fac}}}\right)-V_{\mathrm{ac}_{\mathrm{ref}}}-i q_{-r e f}\left(\frac{k_{\mathrm{droop}}}{1+s T}\right)\right)\left(\frac{k_{\mathrm{ac}}+1}{s T_{\mathrm{ac}}}\right)
\end{gathered}
$$

$T_{\text {fdc }}$ and $T_{\text {fac }}$ are the low-pass filter time constant. $\mathrm{K}_{\text {droop }}$ is the gain of the voltage control loop, $T$ is time constant of the voltage control loop. $K_{\mathrm{ac}} \& K_{\mathrm{dc}}$ are the constants of the $\mathrm{AC}$ and DC measurement and $T_{\mathrm{ac}} \& T_{\mathrm{dc}}$ are the time constant of $\mathrm{AC}$ and DC measurement. The differential equation can be obtained by converting (15) and (16) from frequency domain to time domain using the Laplace transform. The control scheme utilised in this regard should be able to maintain constant voltage magnitude when dynamic load and generation are connected to the network and particularly in the context of abrupt system disturbances. Fig. 1 illustrates a block diagram of the control system implemented for D-STATCOM control. The proposed controlling scheme with two different functionalities are highlighted in blue box in Fig. 1 .

In the D-STATCOM controller, Vacmeas block facilitates measurement of the three-phase voltage as dynamic voltage reference at the desired location. The Vacf signal takes the reference voltage, Vacmeas blocks input and matches it with $\mathrm{Vac}$ ref signal. If $\mathrm{Vac}$ signal is less than reference voltage stipulated by the Tfac block then $d v a c$ signal sends a positive value to iqref signal. If the control iqref signal is positive, it is subsequently forwarded to mag Limiter block, where it is compared with the limit set in the controller according to the DSTATCOM capacity; if the signal is within the upper and lower limit, the reactive power is injected/absorbed corresponding to that value. The final iq_ref signal is forwarded to VSC as shown in Fig. 1. The iq ref signal feedback its value Vdroop through droop controller, it is compared with the Vac and Vac_ref signal again until the $d v a c$ signal become zero. If Vac signal and vac ref signal match each other, the $i q_{-}$ref signal will not attempt to compensate.

The phase-lock-loop (PLL block) is used to generate an output signal that relates the phase of the control variable in respect to the input reference signal. The $P L L$ utilises a controlled oscillator that synchronises the control variable to the reference network signal. Essentially, the $P L L$ provides a reference for the voltage angle that the D-STATCOM employs to relate voltage and current while calculating the active and reactive powers.

In general, the terminal voltage is varied through an appropriate reactive power correction, facilitated by the iq ref signal (as derived from Vacmeas input block value). The varied terminal voltage is essentially compared to a fixed reference Vac ref, which through the PI controller and phase matching (through the PLL) obtains the desired effective reference signal iq_ref

\section{Analysis}

\subsection{Network modelling}

The network model is implemented on the DIgSILENT power factory platform. There are 74 customers, connected from a 10/0.4 $\mathrm{kV}$ transformer in a radial network topology. In this regard, the LV distribution network considered in [21], as provided in Fig. 2 below, is employed.

As defined in the EN50160 standard [22], the voltage at every bus of the medium- and low-voltage network should be within $\pm 10 \%$ of its nominal value, with $\pm 6 \%$ being employed by the network designers. In Ireland, consistent with EN50438, microgeneration is defined as generation units that can produce 25 $\mathrm{A}$ at $230 \mathrm{~V}$ or $16 \mathrm{~A}$ at $400 \mathrm{~V}$, as for the guidelines published by ESB Networks (Irish DSO) [21]. Here, $11 \mathrm{~kW}$ (single-phase) connected EV loads are in excess of the guidelines published by the ESB. Under current regulations, $20 \% \mathrm{EV}$ load penetration is allowed with crate of $3.68 \mathrm{~kW}$. 


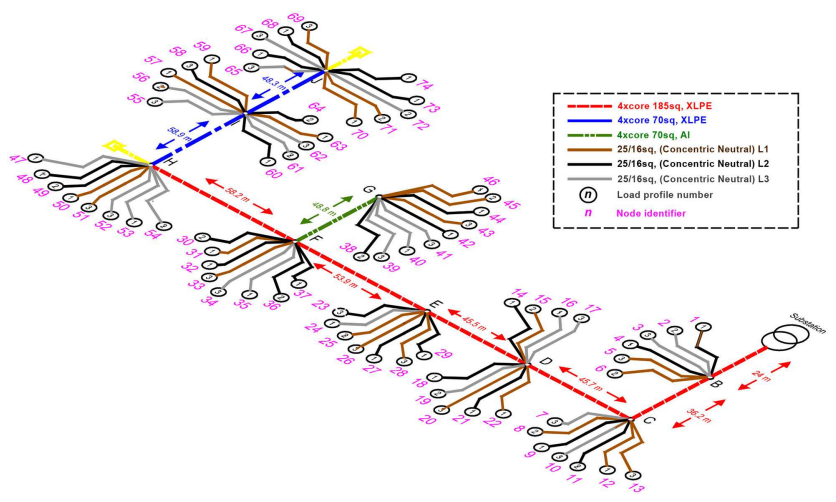

Fig. 2 Section of Irish distribution network [21]

\subsection{Residential and load modelling}

The household load demand profile was obtained from the DSO. The household load is represented by an average ADMD value of $0.49 \mathrm{~kW}$ per customer; based on an annual consumption of electricity of $4300 \mathrm{kWh}$ in Ireland [23] with a power factor for each household load of 0.95 (inductive). With this LV network configuration, a voltage level of $1 \mathrm{p} . \mathrm{u}$ is not achievable. As the main focus of this paper is limited to the analysis of EV penetrations in LV networks, the impact of increased connections of DG on the LV network will be considered in future work.

\subsection{D-STATCOM modelling}

D-STATCOM is connected at Pillar $J$, the furthest point from the grid transformer connection. The D-STATCOM takes an input reference voltage of each individual phase. In an unbalanced network case therefore, the positive sequence voltage of each individual phase is considered. The D-STATCOM model consists of a PWM converter and DC-link capacitor. The DC-link capacitance can provide reactive power support of 0.35 MVAr. The contribution from the DC-link capacitance increases/decreases with differences between the energy delivery and energy absorbing (LV network) systems. The variation of power delivery to the DC-link or absorption from DC-link is something to be determined by the input and output of the connected system [24]. The power delivered to the DC-link is equal to the product input voltage, current and is time varying. However, the power required by the consumer load is constant. Thus, DC-link capacitance buffers the power difference between time varying power delivered and power utilised by the load [24]. If the DC-link capacitance value is reduced (not based on connected network requirement), the ripple voltage on DC link will increase.

In the simulation of the D-STATCOM model, the switching devices, modulation process, and DC capacitor dynamics are considered. Based on VSC model simplified control equations, firing angle and the modulating amplitude only consider input and output variables [20]. Harmonic distortion analysis and transient analysis are out of scope of this work.

\subsection{Electrical vehicle load modelling}

The standard charging profile considered for simulation and analysis are presented in Table 1. The first column indicates the distance that an EV car can travel (in kilometres) before charging is required. The second column presents the power consumption of the EV battery during travelling. The third, fourth, fifth, and sixth columns indicate the time duration required to charge the EV battery completely with different types of chargers (Single or three phase). The amount of charging energy required by the vehicle to travel the desired distance is presented therein. If one assumes that a car travels $10 \mathrm{~km}$, it will therefore require $1.4 \mathrm{kWh}$ of energy and ' 3 phase $400 \mathrm{~V}-16 \mathrm{~A}$ '. An $11 \mathrm{~kW}$ charger can provide the same charge in $8 \mathrm{~min}$. The EV initial State of Charge (SOC) is based on time duration that the car is connected to the network. 'Singlephase $230 \mathrm{~V}-10$ A' $2.3 \mathrm{~kW}$ charger can charge (in respect to this $10 \mathrm{~km})$ in $37 \mathrm{~min}(1.4 \mathrm{kWh}$ of energy). Charging profiles of EVs
Table 1 Charging Specification of EV [26]

\begin{tabular}{|c|c|c|c|c|}
\hline $\begin{array}{l}\text { Distance } \\
\text { travel, km }\end{array}$ & $\begin{array}{c}\text { Charging } \\
\text { energy, kWh }\end{array}$ & $\begin{array}{c}230 \mathrm{~V} / 10 \\
\mathrm{~A} 2.3 \mathrm{~kW} \\
\text { (time) }\end{array}$ & $\begin{array}{c}230 \mathrm{~V} / 16 \\
\text { A } 3.68 \mathrm{~kW} \\
\text { (time) }\end{array}$ & $\begin{array}{c}3 \times 230 \\
\mathrm{~V} / 16 \mathrm{~A} 11 \\
\mathrm{~kW}(\text { Time })\end{array}$ \\
\hline 10 & 1.4 & $00: 37$ & $00: 23$ & $00: 08$ \\
\hline 20 & 2.8 & 01:14 & $00: 46$ & $00: 15$ \\
\hline 50 & 7.1 & 03:04 & $01: 55$ & $00: 38$ \\
\hline 100 & 14.1 & 06:08 & $03: 50$ & 01:17 \\
\hline 150 & 21.2 & $09: 12$ & $05: 45$ & $01: 55$ \\
\hline 200 & 28.2 & $12: 17$ & $07: 40$ & 02:34 \\
\hline
\end{tabular}

can vary depending on battery type, charging equipment, and electricity network. EVs such as the Renault ZOE ZE 40 has a 400 $\mathrm{km}$ range, with a $41 \mathrm{kWh}$ Battery [25]. However, $13 \mathrm{~h}$ would be required to fully charge this EV through a single-phase $3.68 \mathrm{~kW}$ charger based on Table 1. It is not efficient to charge EVs to network for $13 \mathrm{~h}$ for frequent car user. From the DSO prospective, to facilitate the EV customer either the capacity of single-phase charger need to be increased or all household customer need to have three-phase connections. For $11 \mathrm{~kW}$ (three-phase charger), $3 \mathrm{~h}$ and $20 \mathrm{~min}$ would be required to recharge fully. The recent trend of small battery size with high power rating will prompt the Irish DSO to look for different solutions in the range of $7-11 \mathrm{~kW}$ (single phase) in the context of a manageable household load inclusive of charging. In this work, all EV batteries are modelled with a capacity of $20 \mathrm{kWh}$ for $3.68 \mathrm{~kW}$ charging and $40 \mathrm{kWh}$ for $11 \mathrm{~kW}$ charging. For the sake of simplicity, two scenarios are considered. EV batteries are modelled as constant power loads with unity power factor.

\subsection{Investigation period}

In order to demonstrate the benefits of the technique, two specific types of chargers and battery sizes are selected. Based on Fig. 3, a probability density distribution of EV BSOC varies from 0 to 20 $\mathrm{kWh}$. Out of $74 \mathrm{EVs}$ (if each household has an EV, this would represent $100 \%$ penetration), seven EVs are fully charged, and the remaining $(90 \%)$ of EVs retain a state of charge in the range of 0 $90 \%$. The remaining 67 EVs are randomly distributed on different phases on the network. It is noted that $20 \mathrm{kWh}$ and $40 \mathrm{kWh}$ battery sizes are considered for 3.68 and $11 \mathrm{~kW}$ charging, respectively, keeping in mind the recent advancement in battery size. Normally, $11 \mathrm{~kW}$ chargers are connected via three-phase connections to the network. In a UK/Irish context, single-phase connection is employed at domestic level. Therefore, $11 \mathrm{~kW}$ charger is connected to single-phase connection for the purpose of analysis. It is noted in Table 2, Phase B, 26 EVs are connected but only $32.66 \mathrm{kWh}$ of energy is required to fully replenish the battery. Phase A has 24 EVs connected and requires $145 \mathrm{kWh}$ of energy. On average, each EV on Phase A requires $6.04 \mathrm{kWh}$ and require 90 min of charging at $3.68 \mathrm{~kW}$ based on Table 1. The rationale for the simulation time is based on an uncontrolled charging duration. In uncontrolled charging, all EVs are connected simultaneously, although charging time varies based on individual SOC. In this particular scenario, all EVs charging time varies from 37 to $90 \mathrm{~min}$. For the simulations considered, all residential households are randomly assigned an EV. The distribution of the initial BSOC for each EV is shown in Fig. 3. The breakdown of EV allocation is based on a probabilistic distribution as well as energy requirement of the EVs of each individual phase. In the Irish context, real-time charging data are difficult to obtain, so a probability density function (PDF) is applied with a mean of $10.75 \mathrm{kWh}$ and standard deviation of 6 $\mathrm{kWh}$ for initialisation of BSOC [27]. For the $3.68 \mathrm{~kW}$ charger, a battery size of $20 \mathrm{kWh}$ is selected. While $90 \%$ penetration of EVs on a distribution network may be not experienced in reality, it is appropriate to examine the worst case scenarios in order to fully capture the benefits of the control strategy. The approach to define the probability of EVs, BSOC and implementing it to initialisation of EVs as shown in Table 2 and 3 are is taken from the method described by Richardson [27]. 


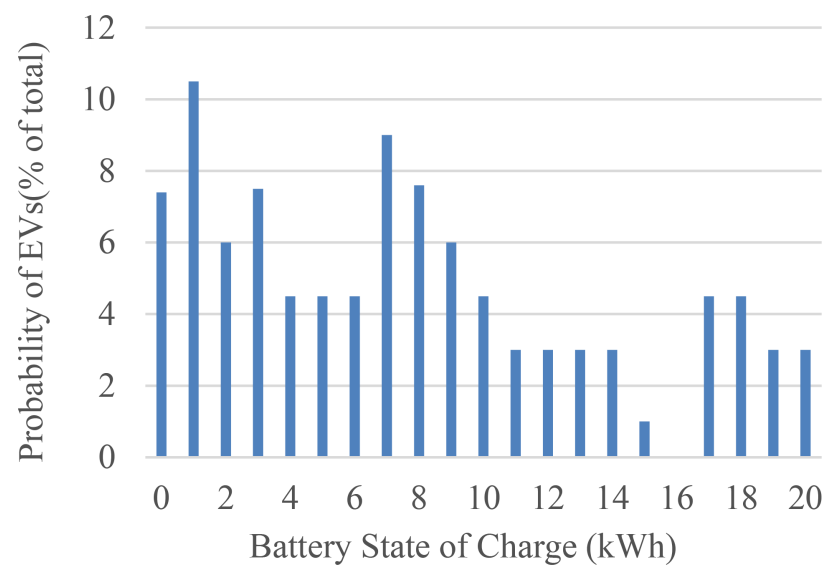

Fig. 3 Distribution of the initial BSOC for each EV [27]

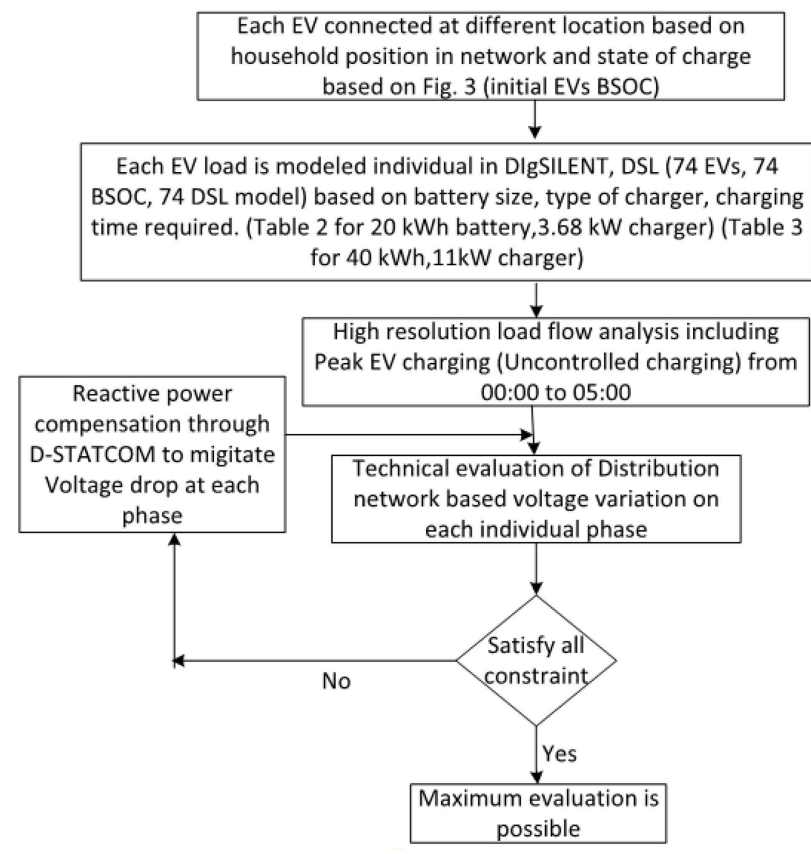

Fig. 4 Technical Evaluation model of EV demand

In Fig. 4, the general technical evaluation model of EV demand is explained. The technical evaluation model is based on the implementation of Fig. 3, Tables 2 and Tables 3 information.

In Fig. 3, the initial BSOC of 74 EVs, connected randomly in the distribution network, is considered. As illustrated in Fig. 3, three of the EVs have $20 \mathrm{kWh}$ of initial BSOC ( $20 \mathrm{kWh}$ battery), so if these three EVs are connected to the network, the net energy requirement of these EVs is zero. For example, if $7 \mathrm{EVs}$ have 0 $\mathrm{kWh}$ of initial BSOC $(20 \mathrm{kWh}$ battery and $20 \mathrm{kWh}$ of energy from $3.68 \mathrm{~kW}$ charger), $5 \mathrm{~h}$ are required for charging. To simplify this complexity of each EV BSOC, EV batteries are randomly placed on the distribution network. Then for each phase, the number of EVs connected, total battery capacity, total BSOC, and energy required is calculated. It is noted that each phase will have a different number of EVs connected and different energy requirements. For instance, Phase $\mathrm{C}$, in Table 2 required $100 \mathrm{kWh}$ for $24 \mathrm{EVs}$, on average it required $4.16 \mathrm{kWh}$ and according to Table 1, they require $60 \mathrm{~min}$ of charging with $3.68 \mathrm{~kW}$ to replenish battery completely. For an individual car example with a $40 \mathrm{kWh}$ battery and an EV BSOC of $60 \%(24 \mathrm{kWh})$, to facilitate the $40 \%$ battery capacity $16 \mathrm{kWh}$ is required. According to Table 1 , a 11 $\mathrm{kW}$ charger can provide $16 \mathrm{kWh}$ of energy in 90 min. Similarly, if battery size is $20 \mathrm{kWh}$ and the EV battery is $60 \%(12 \mathrm{kWh})$ charged, for the remaining $40 \%$ ( $8 \mathrm{kWh}$ ), according to Table 1 , a $3.68 \mathrm{~kW}$ can provide $12 \mathrm{kWh}$ of energy in $2 \mathrm{~h}$. Once the battery on particular phase is fully replenished, it will be automatically disconnected from the network. Each EV load is programmed in
Table 2 Initial of EV (20 kWh battery)

\begin{tabular}{lcccc}
\hline & $\begin{array}{c}\text { Number of } \\
\text { EVs }\end{array}$ & $\begin{array}{c}\text { Combined } \\
\text { battery } \\
\text { capacity, kWh }\end{array}$ & $\begin{array}{c}\text { Combined } \\
\text { initial BSOC, } \\
\text { kWh }\end{array}$ & $\begin{array}{c}\text { Total energy } \\
\text { required, } \\
\text { kWh }\end{array}$ \\
\hline phase a & 24 & 480 & 335 & 145 \\
phase b & 26 & 520 & 487.33 & 32.66 \\
phase c & 24 & 480 & 380 & 100 \\
total & 74 & 1480 & 647 & 277.66 \\
\hline
\end{tabular}

Table 3 Initial of EV (40 kWh battery)

\begin{tabular}{lcccc}
\hline & $\begin{array}{c}\text { Number of } \\
\text { EVs }\end{array}$ & $\begin{array}{c}\text { Combined } \\
\text { battery } \\
\text { capacity, kWh }\end{array}$ & $\begin{array}{c}\text { Combined } \\
\text { initial BSOC, } \\
\text { kWh }\end{array}$ & $\begin{array}{c}\text { Total energy } \\
\text { required, } \\
\text { kWh }\end{array}$ \\
\hline phase a & 24 & 960 & 670 & 290 \\
phase b & 26 & 1040 & 974.66 & 65.33 \\
phase c & 24 & 960 & 760 & 200 \\
total & 74 & 2960 & 2404.66 & 555.33 \\
\hline
\end{tabular}

DIgSILENT in the Dynamic simulation language (DSL) environment in such a way that once BSOC is $100 \%$, it will automatically get disconnected from the network.

\section{Results and discussion}

\subsection{Voltage profile at $3.68 \mathrm{~kW}$ charger}

EV charging load is simulated in a test LV network with 74 houses in Dublin, Ireland. It is supplied with single-phase $230 \mathrm{~V}$ (line to phase voltage) via a distribution transformer with power rating of 0.4 MVA. In test system, the distribution system's model in DIgSILENT power factory. The purpose, in this regard, is to get better appreciation of the voltage unbalance or voltage profile and associated breaches.

Results are presented such that the voltage profile response throughout the network is prioritised, while EV charging is taking place. In this regard, the voltage of each individual phase at Pillar B, Pillar E, and Pillar J (respectively, representing the start, middle and end of the network line) are presented over the period 00:00 05:00. The voltage profile is calculated for the $5 \mathrm{~h}$.

It is observed that a voltage drop below 0.95 p.u (without DSTATCOM intervention) can occur at pillar J. The grid is unable to maintain the voltage profile while abrupt EV load is connected on each individual phase. The voltage drop on Pillar J, as presented in Fig. 5, clearly presents the limitation of the grid to overcome abrupt changes in load. D-STATCOM is however able to compensate but support is provided in this regard to nearby pillars rather that those further away. All households have EV charging connection available. All households have EVs but based on PDF, eight EVs are already fully charged. In the simulations, all EV loads are connected simultaneously to consider the maximum impact of EV battery charging load on the network. The relative positioning of these EVs are considered based on household load connected in distribution network.

Fig. 2 illustrates the connection of each household load and EV battery load connected to distribution network. The controlling technique utilises reactive power only to support voltage drop. The voltage profile of each phase is measured at three different locations across the network: close to the transformer (pillar B), at the centre (relatively) of the network (pillar E), and at the end of the network (pillar J) as shown in Fig. 2. Pillar B is located next to the transformer and as a consequence, displays less sensitivity to additional EV load as it is located at the network connection. Pillar $\mathrm{J}$ is located at the end of the network. If the D-STATCOM is placed at pillar J. The impact of D-STATCOM on voltage profile of individual phase is maximised at pillar $\mathrm{J}$ but pillar B is less sensitive to it because it is furthest away from the D-STATCOM. D-STATCOM is placed at pillar $\mathrm{J}$ as the maximum voltage drop is expected at the end of the (radial) network. In Fig. 5, voltage profile of individual phases with respect to battery size and charger, over a $5 \mathrm{~h}$ analysis duration is presented. If the BSOC is 

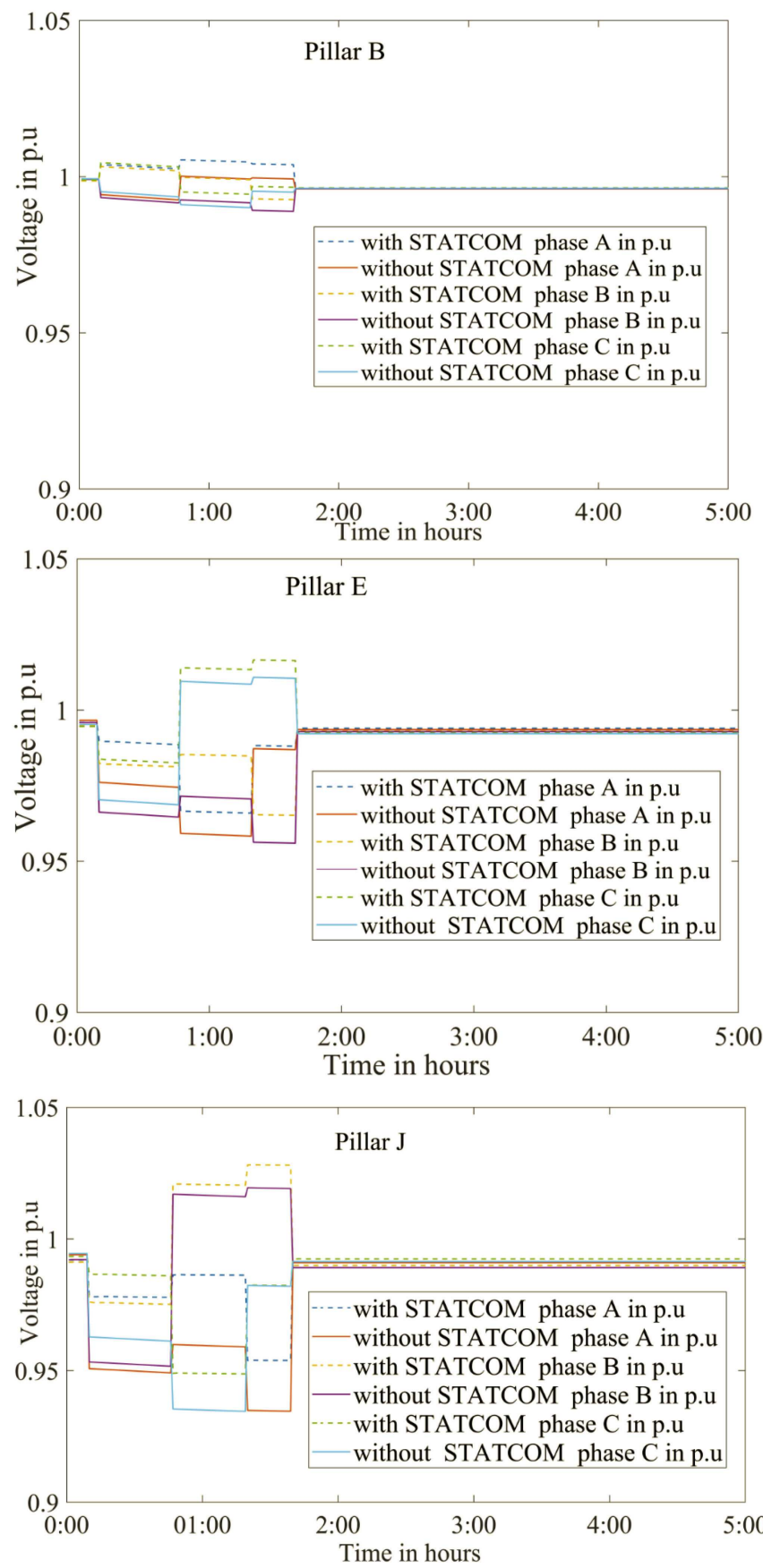

Fig. 5 Network Voltage with and without D-STATCOM at pillar B, Pillar $E$ and Pillar J at $3.68 \mathrm{~kW}$ charging

randomised, there will be sufficient time (within a $2 \mathrm{~h}$ frame of reference) to charge all EV batteries completely. When all EVs are connected simultaneously, the voltage drop occurs in all individual phases and can be seen in Fig. 5. D-STATCOM is able to maintain the voltage level across all phases within limits, with a slight overvoltage on Phase B at Pillar J instead of reducing it. DSTATCOM injects reactive power in the network because Phase A and Phase $\mathrm{C}$ are overloaded and face an under voltage condition at same instant. It can provide reactive power support to all the phase simultaneously if required (individual phase support is not possible)

\subsection{Voltage profile at $11 \mathrm{~kW}$ charger (single phase)}

The effect on voltage profile as a consequence of EV penetration is presented in Fig. 6. In this scenario, 90\% EV penetration means 67 residential households have EVs connected. The specific worstcase scenario considered in this research is in respect to EV charging in order to highlight the advantages of D-STATCOM. Here, $11 \mathrm{~kW}$ charger is connected to the individual phase of each
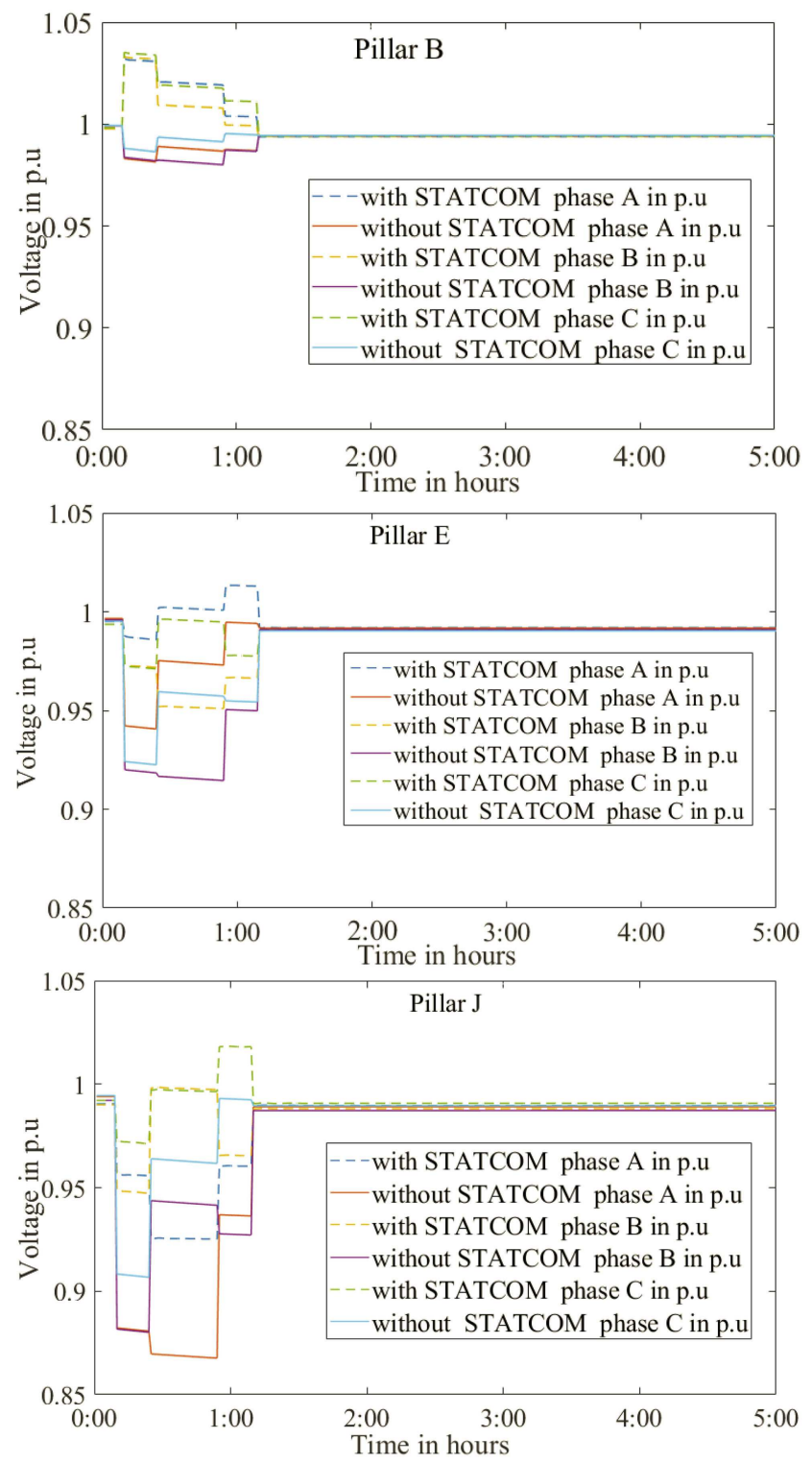

Fig. 6 Network Voltage with and without D-STATCOM at pillar B, Pillar E and Pillar $J$ at $11 \mathrm{~kW}$ charging

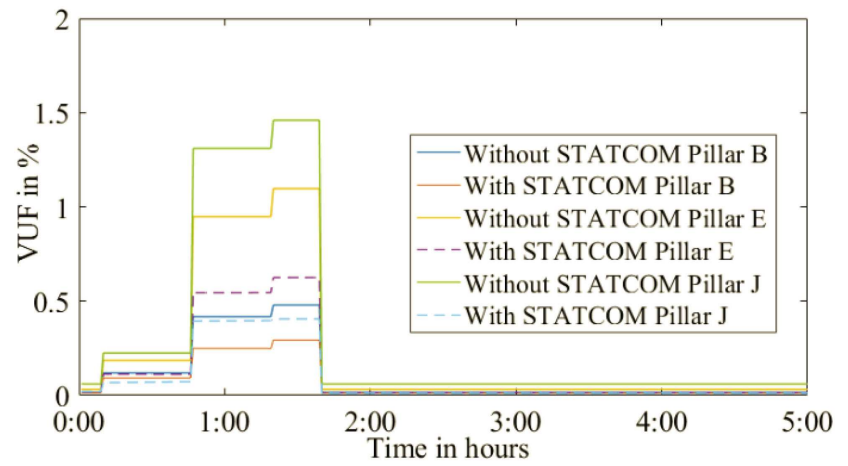

Fig. 7 Reactive power injected by STATCOM at Pillar J at 3.68 and $11 \mathrm{~kW}$ chargers

household, Fig. 6 illustrates the voltage profile at pillars B, E, and $\mathrm{J}$, respectively, in terms of EV load. D-STATCOM is unable to maintain the voltage range between 0.95 and 1.05 p.u, on Phase A at Pillar J. The breaches are presented in Fig. 6. In fact the voltage breach during 00:00 am to 01:00 am are out of the range or power capacity of the D-STATCOM. The D-STATCOM injects $0.4 \mathrm{MVAr}$ into the network at the same instant as shown in Fig. 7 but the voltage at Phase $\mathrm{A}$ is only able to recover from 0.87 to 0.93 p.u on Phase A.

IET Gener. Transm. Distrib., 2019, Vol. 13 Iss. 7, pp. 951-959 (c) The Institution of Engineering and Technology 2019 


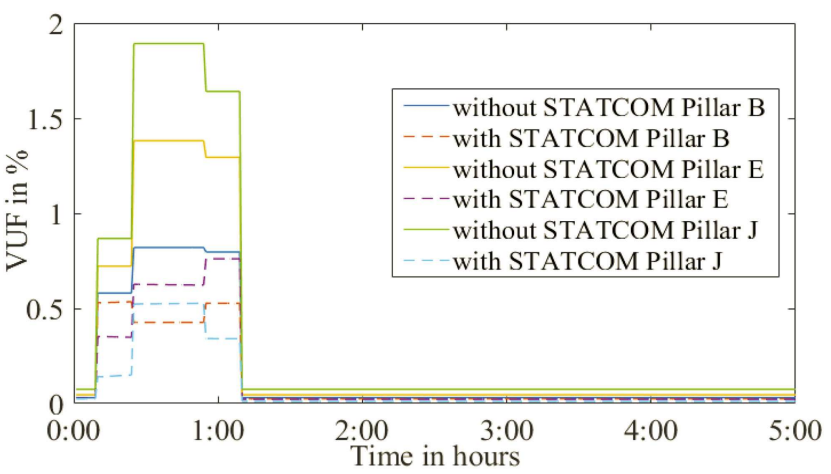

Fig. 8 Voltage Unbalance Factor (VUF) at Pillar B, Pillar E and Pillar J at $3.68 \mathrm{~kW}$ charging

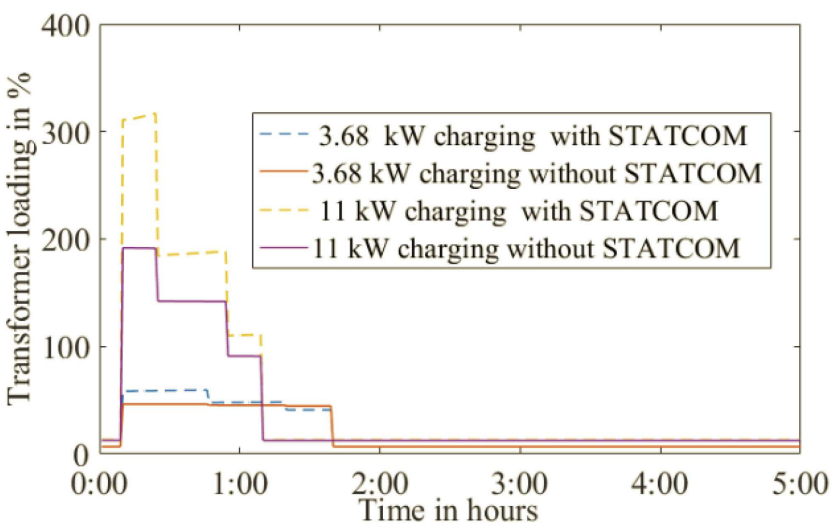

Fig. 9 Voltage Unbalance Factor (VUF) at Pillar B, Pillar E and Pillar J at $11 \mathrm{~kW}$ charging

The results suggest that EV penetration closest to the upstream MV grid, in the context of an exemplar urban distribution network, will have less impact on voltage profile than EVs connected to the far end of the radial network. The voltage profile across the network will vary according to location and rating of EVs. EVs are connected to the network as single-phase load, but as such, they can impact voltage level on all (three) phases with the voltage unbalance factor also being affected. Under the conditions considered (April, 2012) in terms of the consumer demand, voltage breaches were not observed until the high penetration of EV connected simultaneously in the network. D-STATCOM, however, is able to reduce voltage drop quick effectively and as such also serves to reduce voltage fluctuations in the network.

\subsection{Voltage unbalance factor}

Single-phase penetration of EV can cause voltage unbalance in low-voltage networks. For DSOs, maintaining power quality is a big concern in the context of increasing EV connections. From a voltage profile perspective, voltage drop and voltage unbalance can cause damage to electrical equipment. This is particularly the case with voltage unbalance caused by increased single-phase connected EV. The voltage unbalance factor (VUF) is defined by the IEEE [28] as

$$
\mathrm{VUF} \%=\left|\frac{V_{-}}{V_{+}}\right| \times 100
$$

where $V_{-}$is the negative sequence component and $V_{+}$is the positive sequence component of the voltage. According to the IEEE standard [29], voltage imbalance must be limited to $2 \%$ in low-voltage and medium-voltage networks for $95 \%$ of the time. EV connections in LV networks could result in one phase having more load connected relative to the other two.

Fig. 8 illustrates the voltage unbalance profile over the benchmark of $5 \mathrm{~h}$ for the test distribution network on different pillars at $3.68 \mathrm{~kW}$ EV charging scenarios. The D-STATCOM is able to reduce the VUF. It is evident that the VUF value is reduced

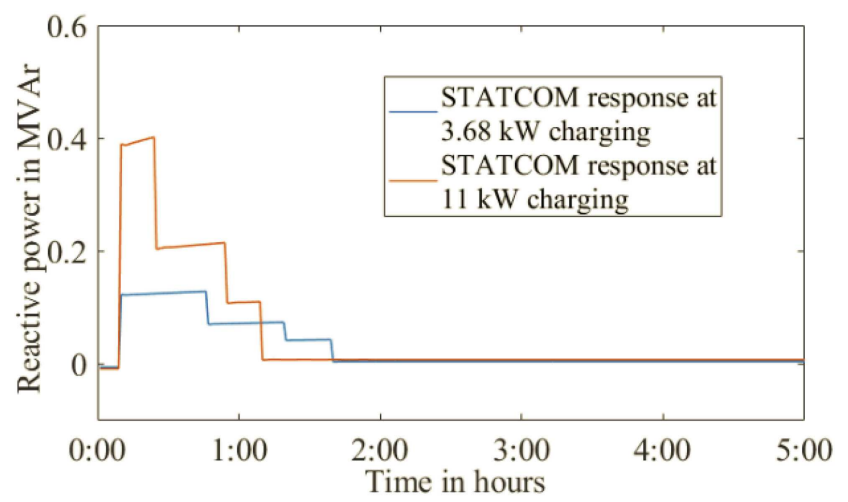

Fig. 10 Transformer loading at 3.68 and $11 \mathrm{~kW}$ chargers, with and without D-STATCOM on complete network

meaningfully during the EVs charging period. The EVs are placed randomly, so one phase has more EVs connected than the other two phases, based on Table 2 and Table 3. In short, D-STATCOMs have ability to reduce VUF while EVs are available in the network.

Fig. 9 illustrates the voltage unbalance profile over the benchmark of $5 \mathrm{~h}$ for the test distribution network on different pillars at $11 \mathrm{~kW} \mathrm{EV} \mathrm{charging} \mathrm{scenarios.} \mathrm{The} \mathrm{VUF} \mathrm{do} \mathrm{not} \mathrm{breach}$ the limit of $2 \%$ at 3.68 and $11 \mathrm{~kW}$ charging in the network, but $1.7 \%$ VUF at $11 \mathrm{~kW}$ charging is quiet high value. VUF is reduced on all individual phases quiet significantly. The D-STATCOM, therefore, has the ability to reduce VUF in all conditions.

\subsection{Transformer loading analysis}

The thermal loading of the transformer is presented in Fig. 10. Prior to the penetration of EVs, the majority of loading measurements are found to lie in between 10 and $15 \%$ of normal household load. In the case of a $3.68 \mathrm{~kW}$ charger, the transformer loading remains between 45 and $60 \%$, approximately. The $11 \mathrm{~kW}$ single-phase charger increases the loading drastically from 11 to $183 \%$ approximately due to high penetration of EV load at $11 \mathrm{~kW}$ charging (as shown in Fig. 10). The transformer loading can be reduced if fewer EVs are connected to the network. Reducing the EV penetration from 100 to $30 \%$ is considered so that along with the D-STATCOM, loading is $\sim 52 \%$. In this network, with current power rating of the transformer (0.4 MVA), 20 to $30 \%$ of EV penetration with $11 \mathrm{~kW}$ charger can be sustained. Overloading of network cables and the associated transformer needs to be considered while installing compensation devices in distribution network.

\subsection{Reactive power injected through D-STATCOM}

The D-STATCOM is connected to the Pillar J. Reactive power injected by the D-STATCOM during 3.68 and $11 \mathrm{~kW}$ charging with $90 \%$ EV penetration scenarios are shown in Fig. 7. The STATCOM injects a maximum 0.4 MVAr for $90 \% \mathrm{EV}$ penetration at $11 \mathrm{~kW}$ charging. The sizing of a STATCOM is dependent on the requirement based on the needed MVAr amount to support the network. In this particular network, 90\% EV penetration can be overcome through 0.4 MVAr-rated reactive power compensation device but the transformer need to upgrade to higher power rating from 0.4 to 0.8 MVA.

Optimal placement of custom power devices like D-STATCOM and DVR is comprehensively discussed in [10]. While that study is based on steady-state analysis, the best results obtained are when D-STATCOM is placed at $2 / 3 \mathrm{rd}$ of the feeder length (from the distribution network transformer perspective). In this study, the rationale is optimal sizing of D-STATCOM rather than placement in terms of a dynamic analysis (Temporal analysis), and the amount of reactive power required to mitigate power-quality concerns, when $90 \%$ of EV integrated at $11 \mathrm{~kW}$ single-phase chargers are connected at same instance. For instance for the UK/Irish DSO's to sustain $90 \%$ of EV penetration requires 0.4 MVAr reactive power D-STATCOM, as shown in Fig. 7, to be installed. 


\subsection{Economical justification}

Currently, the D-STATCOM technology is in a development phase. In this work, D-STATCOM is tested based on paradigm shift of policy planning between Transmission System Operator (TSO) and DSO. If DSO are to implement the technology throughout the LV network, the cost could reduce substantially. In the UK, there is a policy shift and Ofgem (Office of Gas and Electricity Markets) [30] are introducing a network regulation model based on RIIO (Revenue using Incentives to deliver Innovation and Outputs). The current electricity distribution price control RIIO-1 will end in 2023. The next phase RIIO-2 will establish more onerous and stringent conditions on network companies to deliver innovation, reliability, and investment at the least cost to consumers. It is noted that incentives are given to companies which can integrate more LCTs in network or increase prosumer [31]. So, the revenue of the company is increased substantially based on penetration levels of LCTs. In an Irish policy context, TSO (EirGrid) and DSO (ESB network) are working together to make the network more secure and sustainable under the pilot of DS3 [32]. The main objective therein is to maintain voltage level throughout the transmission and distribution network.

The focus here is to establish the extent that a D-STATCOM can offer a viable means to alleviate voltage concerns across a distributed network with a significant number of EV connections. Other mitigation solutions, such as OLTC transformers, network reinforcement, capacitor banks, and PV inverter control are well established as viable means of voltage support. Indeed, these approaches to voltage violation mitigation can be cost-effective, but in the context of an increasingly stochastic and variable $\mathrm{P} / \mathrm{Q}$ environment (exacerbated by the inclusion of $\mathrm{EV}$ ), alternative solutions are needed. This paper therefore investigates if a solution originally devised for transmission networks can also be a solution for distribution networks. From a UK/Irish perspective, a comprehensive economic analysis, based on mitigating solutions such as OLTC, network reinforcement in the context of three-phase LCT connections is available in [33]. The report suggests that OLTC transformers are able to accommodate $100 \%$ of EV in the network at normal/slow charging rates, but the upgrade cost of transformer is $£ 60,000$ [33]. The authors considered economic analysis for each LCT technology (PV, EV, CHP) at different penetration levels. One of the outcomes of that research was that for UK/Irish DSOs, to sustain $90 \%$ of EV penetration, a DSTATCOM facilitating 0.4 MVAr reactive power is required. The cost of such a device was ascertained to be $\$ 28,000(\sim £ 22,000)$ [34]. The authors identified in their report that the cost associated would be the same for an inverter with similar capacity to DSTATCOM [34] and for a similarly rated capacitor bank, the authors suggest an installation cost of $\$ 4000(\sim £ 3200)$ [34]. It is to be noted that in the context of inverter or capacitor back options, the installation and maintenance cost are not included in the cost estimations. The authors concede that a D-STATCOM may not be the most cost-effective solution, but as a leverage for enhanced controllability and response time, it could be an optimal approach in a $P / Q$ environment characterised by increasing $\mathrm{EV}$ installations.

\section{Conclusion}

A major concern in relation to $\mathrm{EV}$ penetration in distribution networks is voltage magnitude control. This paper describes the mechanism of the voltage support and the possible mitigation solutions through reactive power compensation. In this report, DSTATCOM is employed in a distribution network to support EV penetration. In this regard, testing against the worst possible loading scenarios in terms of how voltage magnitude might be affected. With $90 \%$ EV penetration, the results show that voltagelevel compensation of each phase in unbalance network is achievable. The voltage limit $(0.95-1.05$ p.u $)$ is defined in EN 50,438 standard [34] and IEEE standard [35], and this tolerance is not breached while D-STATCOM is connected to the pillar J. The voltage magnitude regulation limit can be maintained more precisely up to 1 p.u if higher power rating D-STATCOM is selected. In practical environments, the D-STATCOM capacity range available is $350-19,500 \mathrm{kVAr}$ for $480 \mathrm{~V}-46 \mathrm{kV}$ grid $\mathrm{AC}$ connection [36].

The paper summarises the voltage drop mitigation methods developed using D-STATCOM against the effects of EVs penetration. The concept implemented is to employ the DSTATCOM reactive power compensation, in conjunction with a DC-link capacitor bank. This control methodology can effectively control the voltage on each phase of three-phase unbalanced distribution network. The aim of this work therefore is to model the controllability of the LV distribution networks, in the context of voltage profile management, by using a D-STATCOM. EV integration scenarios are considered in this regard. This analysis facilitates a prediction concerning an enhanced potential for EV in respect to deferring the potential impacts such reactive power compensation could have on the distribution network.

\section{References}

[1] Georgiev, P.: 'How to get rid of dirty diesels on city roads', Transp. Environ., 2018

[2] Bruge, P., Guida, U., Goralczyk, M.B.: 'ZeEUS eBus Report An overview of electric buses in Europe', ZeEUS project, Brussels, 2016

[3] Liu, H., Yang, Y., Qi, J., et al.: 'Frequency droop control with scheduled charging of electric vehicles', IET Gener. Transm. Distrib. Spec. Issue: Distrib. Auton. Dispatch Control Act. Distrib. Netw. /Microgrids Potential Scheme Realise Plug Play DER, 2017, 11, (3), pp. 649-656

[4] Esmaili, M., Rajabi, M.: 'Optimal charging of plug-in electric vehicles observing power grid constraints', IET Gener. Transm. Distrib., 2014, 8, (4) pp. 583-590

[5] Celli, G., Pilo, F., Soma, G., et al: 'A comparison of distribution network planning solutions: traditional reinforcement versus integration of distributed energy storage'. PowerTech (POWERTECH), Grenoble, 2013

[6] Hua, J., Marinellia, M., Coppo, M., et al.: 'Coordinated voltage control of a decoupled three-phase on load tap changer transformer and photovoltaic inverters for managing unbalanced networks', Electr. Power Syst. Res., 2016, 131, pp. 264-274

[7] Safayet, A., Fajri, P., Husain, I.: 'Reactive power management for overvoltage prevention at high PV penetration in low voltage distribution system'. IEEE Energy Conversion Congress and Exposition (ECCE), Montreal, QC, Canada, 2015

[8] Efkarpidis, N., De Rybel, T., Driesen, J.: 'Technical assessment of centralized and localized voltage control strategies in low voltage networks', Sust. Energy, Grids Netw., 2016, 8, pp. 85-97

[9] Shahnia, F., Ghosh, A., Ledwich, G, et al. 'Voltage unbalance reduction in low voltage distribution networks with rooftop PVs'. 2010 20th Australasian Universities Power Engineering Conf. (AUPEC), 2011

[10] Shahnia, F., Ghosh, A., Ledwich, G., et al.: 'Voltage unbalance improvement in low voltage residential feeders with rooftop PVs using custom power devices', Int. J. Electr. Power Energy Syst., 2014, 55, pp. 362-377

[11] Zhiming, G., Zhenhong, L., Tim, L., et al.: 'Battery capacity and recharging needs for electric buses in city transit service', Energy, 2017, 122, pp. 588600

[12] Pukhrem, S., Basu, M., Conlon, M. 'Probabilistic risk assessment of power quality variations and events under temporal and spatial characteristic of increased PV integration in low-voltage distribution networks', IEEE Trans. Power Syst., 2018, 33, (3), pp. 3246-3254

[13] Beaude, O., Lasaulce, S., Hennebel, M., et al.: 'Reducing the impact of EV charging operations on the distribution network', IEEE Trans. Smart Grid, 2016, 7, (6), pp. 2666-2679

[14] Mwasilu, F., Justo, J.J., Kim, E.-K., et al.: 'Electric vehicles and smart grid interaction: a review on vehicle to grid and renewable energy sources integration', Renew. Sust. Energy Rev., 2014, 34, pp. 501-516

[15] El-Batawy, S.A., Morsi, W.G.: 'Optimal design of secondary distribution system considering electric vehicles high-power residential fast chargers', IET Gener. Transm. Distrib., 2017, 11, (14), pp. 3475-3484

[16] Rafał, K.: 'Control of shunt active power conditioner with energy storage', Warsaw, 2013

[17] Milano, F.: 'Power system and analysis toolbox-documentation for PSAT version 2.0.0', 2008

[18] Cepeda, J., Aguero, E., Colome, D.: 'Programming of simplified models of flexible alternating current transmission system (FACTS) devices using DIgSILENT simulation language', in: 'Power factory applications for power system analysis' (Springer, Basel, Switzerland, 2014), pp. 391-420

[19] Milano, F.: 'FACTS devices', in: 'Power system modelling and scripting (Springer, Berlin, Germany, 2010), pp. 413-434

[20] Milano, F.: 'AC/DC devices', in: 'Power system modelling and Scripting' (Springer, Berlin, Germany, 2010), pp. 395-412

[21] Sunderland, K., Coppo, M., Conlon, M., et al.: 'A correction current injection method for power flow analysis of unbalanced multiple-grounded 4-wire distribution networks', Electr. Power Syst. Res., 2016, 132, pp. 30-38

[22] Markiewicz, H., Klajn, A.: 'Voltage disturbances, standard EN 50160-voltage characteristics in public distribution systems' (Copper Development Association, 2004), http://copperalliance.org.uk/uploads/2018/03/542standard-en-50160-voltage-characteristics-in.pdf, accessed 15th June 2018

[23] CER: 'Comission for energy regulation', 2017. Available at http://www.cer.ie/ electricity-gas/electricity, accessed 11 January 2017 
[24] Chung, H.: 'Minimization of DC-link capacitance in power electonic converter systems', in Chung, H.S., Wang, H., Blaabjerg, F., et al.(Eds.): 'Reliability of power electronic converter systems', (Institution of Engineering and Technology, Stevenage, UK, 2015), pp. 141-163

[25] Available at https://www.renault.ie/vehicles/new-vehicles/zoe.html, Renault, 2017

[26] 'Danskelbilkomite'. Available at http://www.danskelbilkomite.dk/ ladetstandard.htm, accessed June 2018

[27] Richardson, P., Flynn, D., Keane, A.: 'Optimal charging of electric vehicles in low voltage distribution systems', IEEE Trans. Power Syst., 2011, 27, (1), pp. 268-279

[28] Shahnia, F., Majumder, R., Ghosh, A., et al.: 'Voltage imbalance analysis in residential low voltage distribution networks with rooftop PVs', Electr. Power Syst. Res., 2011, 81, pp. 1805-1814

[29] IEEE: 'Std 1159-2009 - IEEE recommended practice for monitoring electric power quality', IEEE, 2009

[30] 'Ofgem', 2018. Available at https://www.ofgem.gov.uk/network-regulationriio-model, accessed 26 June 2018
[31] Frerk, M., Ward, J., Darcy, S.: 'A Low carbon incentive in RIIO2' (Sustainability First, London, 2018)

[32] EirGrid: 'DS3 system services contracts for regulated arrangements', EirGrid, 2017

[33] Navarro Espinosa, A.A.: 'Low Carbon Technologies in Low Voltage Distribution Networks: Probabilistic Assessment of Impacts and Solutions', University of Manchester, Manchester, 2015

[34] Kueck, J., Kirby, B., Rizy, D.T., et al.: 'Reactive power from distributed energy', Electricity, 2006, 19, (10), pp. 27-38

[35] '1547-2003 - IEEE Standard for Interconnecting Distributed Resources with Electric Power Systems', 2003

[36] 'Power quality solutions STATCOM, $100 \mathrm{kVAr}$ to $30 \mathrm{MVAr}$ dynamic reactive power compensation', ABB. Available at https://library.e.abb.com/public/ f911c41e3d625124c1257bf900251f22/PESTATCOM-PHPB01U-EN-

A1_STATCOM-Web.pdf, accessed December 2017 